\title{
Stress Management Based on Trait-Anxiety Levels and Sleep Quality in Middle-Aged Employees Confronted with Psychosocial Chronic Stress
}

\author{
Marion Trousselard ${ }^{1 *}$, Dominique Steiler ${ }^{2}$, Angelique Lebreton ${ }^{1}$, Pascal Van Beers ${ }^{1}$, \\ Catherine Drogout ${ }^{1}$, Josiane Denis ${ }^{1}$, Mounir Chennaoui ${ }^{1}$, Frédéric Canini ${ }^{1}$ \\ ${ }^{1}$ Département des Environnement Opérationnels, IRBA-CRSSA, La Tronche, France \\ ${ }^{2}$ Département Management et Comportements, Grenoble Ecole de Management, Grenoble, France \\ Email: *marion.trousselard@gmail.com
}

Received July 24 $4^{\text {th }}$, 2013; revised October 26 $6^{\text {th }}$, 2013; accepted December $2^{\text {nd }}, 2013$

Copyright $(\subset) 2014$ Marion Trousselard et al. This is an open access article distributed under the Creative Commons Attribution License, which permits unrestricted use, distribution, and reproduction in any medium, provided the original work is properly cited. In accordance of the Creative Commons Attribution License all Copyrights $(\subseteq 2014$ are reserved for SCIRP and the owner of the intellectual property Marion Trousselard et al. All Copyright $@ 2014$ are guarded by law and by SCIRP as a guardian.

\begin{abstract}
A stress management program using cardiac coherence was implemented after an organizational downsizing. The study was conducted in nine voluntary workers in order to evaluate the efficiency of the program. A baseline evaluation was conducted on psychological variables (anxiety, perceived-stress, wellbeing and sleep), endocrine assessments (urinary cortisol excretion, alpha-amylase and salivary concentrations) and physiological recordings (sleep and heart rate variability). The low number of participants was due to the intrusive approach in collecting physiological and endocrine variables. The program consisted of ten sessions of cardiac coherence training during a 3-month follow-up period. At the end of the training sequence, subjects were once again exposed to the same evaluation battery. A decrease in perceived stress and a subsequent increase in well-being were observed. Sleep quality improved as suggested by the results of the subjective and objective measurements. For the entirety of the results, improvements were higher in subjects with high vs. low trait-anxiety scoring. The pattern of results for subjects prone to a high level of trait-anxiety suggested that stress and sleep are related to each other in a bidirectional way: increased anxiety is associated to poor sleep and stress reduction improves both anxiety and sleep. On the basis of these results, we suggest that trait-anxiety can be used as an indicator of which employees should be given priority for stress management intervention. We will also highlight the interest of operationally physiological recordings, used outside the laboratory, for measuring objective improvements due to this stress management intervention, as quality of sleep.
\end{abstract}

Keywords: Anxiety; Work Stress; Sleep; Stress Management

\section{Introduction}

A growing body of evidence indicates that downsizing and its related forms of organisational restructuring can have profound adverse effects on worker safety, health and well-being through stress (Bourbonnais et al., 2005; Kalimo et al., 2003; Kang et al, 2004; Vahtera et al., 2004).

The reaction of individuals to chronic stress is theorized in the general alarm syndrome and allostasis theories (Sterling \& Eyer, 1988), conducting to high biological cost featuring the allostatic load (Chrousos, 2009). Stress underpins a number of disturbances often found in a psychosocial stress context. Psychosocial stressor exposure is associated with an enhanced Hypothalamo-Pituitary-Adrenal (HPA) axis as shown by the increase in cortisol reaction (Biondi \& Picardi, 1999; Chida \& Hamer, 2008; Chida \& Steptoe, 2009).

The Autonomic Nervous System (ANS) with its two sympathetic and parasympathetic branches is also activated in stress-

${ }^{*}$ Corresponding author. ful conditions with an increased sympathetic tonus, a decrease in parasympathetic tonus and reduced heart rate variability (HRV) (Friedman \& Thayer, 1998; Porges, 1995). Such a pattern is also observed in psychosocial strain situation (Horsten et al., 1999; Ohira et al., 2008). An appropriate vagal response therefore involves high vagal flexibility that both allows sympathetic activity to occur and limits its activation to the period of stressors presence. Consequently, healthy physiology could be features of high levels of adaptative variability (Lucini et al., 2002; Porges, 1995).

Subjects exposed to psychosocial stressors also experienced emotional disturbance centered by anxiety levels (Lazarus, 1993; Poleshuck et al., 2009). This anxiety is both the consequence of previous stressor exposures (Haftgoli et al., 2010; Poleshuck et al., 2009) and a factor of vulnerability for future stressor exposures (Hanson \& Chen, 2010; Boyce \& Ellis, 2005). Subjects with high levels of trait-anxiety typically respond to stress with greater elevations of cognitive and physiological arousal, impairment of motor performance, and health 
disorders compared with subjects who have low levels of traitanxiety (DeMoja \& DeMoja, 1986; Grillon et al., 1993; Haftgoli et al., 2010; Sade et al., 1990; Poleshuck et al., 2009). The negative effects of trait-anxiety (TA) may be attributed to the tendency to respond fearfully to a wide variety of unspecific stressors, and the need for both security and cognitive control (Fales et al., 2008; Spielberger, 1966, 1970, 1975). In this way, state-anxiety could correspond exactly to mood variations (Bolmont \& Abraini, 2001). Presumably people are always experiencing a continuous stream of affects, manifesting itself in some sort of mood, which provides a background to everyday activities (Watson \& Clark, 1994).

Then exposure to psychosocial stressors may also induce sleep disorders as indicated by a growing amount of literature on the associations between stressful workplace experiences and sleep problems (Linton, 2004; Nakata et al., 2004; Kalimo et al., 2000; Akerstedt et al., 2002; Marquie et al., 1999; Jacquinet-Salord et al., 1993). The inability to stop worrying about work during free time may be an important link in the relationship between stress and sleep (Akerstedt et al., 2002).

Pharmaceutical approaches have been developed to regulate the endocrine and SNS imbalances and to therefore improve health and quality of life for working people (Head \& Kelly, 2009). A combination of certain attitudes and behaviour constitutes a more natural approach based on physical training, sleep rest strategies, or dietary and nutritional strategies. Other forms of mental training, such as yoga, martial arts, meditation, and creative courses are also in common use (Carlson \& Garland, 2005). Education and training, as well as the use of external information processing devices, may be labelled as "conventional" means of reducing stress. They are often well established and culturally accepted. Research exploring the impact of the regulation of emotions on physiological processes is still relatively scarce in the context of work restructuring (McCraty et al., 2003). The capacity to both self-reduce negative emotions and self-generate positive emotional states however, can be developed confronting stress in changes at work and refined through the use of practical tools and techniques quickly enhancing a shift to a physiologically quiet state by increasing parasympathetic flexibility (Porges, 1995).

In line, techniques for enhancing heart/brain synchronization (Heart Coherence, Cardiac Coherence (CC)), facilitating the maintenance of a physiologically efficient and highly regenerative inner state, characterized by reduced nervous system chaos and increased synchronization and harmony in systemwide dynamics have been developed. This psychophysiological mode, termed physiological coherence, is conducive to healing and rehabilitation, emotional stability and optimal performance (McCraty et al., 1995; McCraty et al., 1998). Recent research has demonstrated that HRV dynamics are particularly sensitive to changes to emotional state, and that positive and negative emotions can be readily distinguished by changes in heart rhythm patterns, which are independent to the heart rate (McCraty et al., 2003; McCraty et al., 1998). More specifically, during the experience of negative emotions such as anger, frustration, or anxiety, heart rhythms become more erratic or disordered, indicating less synchronization in the reciprocal action between the parasympathetic and sympathetic branches of the autonomic nervous system. In contrast, sustained positive emotions, such as appreciation, love, or compassion, are associated with a highly ordered or coherent pattern in the heart rhythms, reflecting greater synchronization between the two branches of the autonomic (Tiller et al., 1996). An important reason that this technology is effective is that it uses HRV feedback for reflecting the activity of both the sympathetic and parasympathetic branches of the autonomic nervous system and the synchronization between them, and thus providing a window into the dynamics of the system 2 as a whole. Compared to EEG feedback, HRV feedback is also considerably simpler and more straightforward to learn and use, which facilitates rapid improvement. Furthermore, because the instrumentation only uses a simple pulse sensor that does not require an electrode hook-up, it is extremely versatile and can be easily and effectively used as an educational tool not only in clinical settings but also in the home, workplace, schools, or even whilst traveling. Its cost-effectiveness also makes it accessible to a greater number of people and in a wide range of applications (McCraty et al., 2003). In relation to other biofeedback modalities, HRV feedback also reflects changes in emotional/psychological state for subjects (Lehrer et al., 2003; McCraty et al., 1998; McCraty \& Tomasino, 2004).

As reducing stress and increasing emotional stability and quality of sleep are critical for dealing with organisational restructuring, the aim of the present study is to evaluate the benefits of the use of an intervention based on physiological coherence in a sample of middle-aged workers confronted with organisational changes by answering four specific questions. The first question concerns the physiological and psychological stress level benefits of the intervention. How such an intervention impacts the subjective and objective quality of sleep is the second assessed question. Third, faced with the intervariability observed in monitoring stressors, the third one examines how trait-anxiety modulates the stress and sleep responses to the intervention program. Finally, the last question concerned testing the feasibility, as acceptance for subjects, and the interest, of "light" physiological recordings used outside the laboratory for evaluating benefits of such an intervention. We assume that cardiac coherence training will increase the positive assessed outcomes and will reduce the negative assessed outcomes. We also assume that the improvement of the emotional functioning will be better for the more anxious subjects. Finally, whether subjects accept the "light" physiological recordings used outside the laboratory could depend on individuals.

\section{Materials and Method}

\section{Participants}

A research laboratory, employing 160 personnel, submitted to downsizing and related forms of organisational restructuring in the following two years was contacted for the study. Individuals of the lab received a letter inviting men (90 subjects from the research lab) to participate in the study. The letter was supported by a covering letter from the management, and contained three types of information. First, the main aim of the study was noted as a psycho-physiological investigation based on questionnaires about stress and physiological recordings, with guidance for the protocol for the experiment. Second, the desired criteria to be included in the study were defined as: being male, not to be undergoing treatment and not to have practiced stress intervention since the announcement of the restructuration of the laboratory. Third, the protocol design was clearly described (Figure 1). They were also informed that the study was conducted in accordance with all applicable regu- 


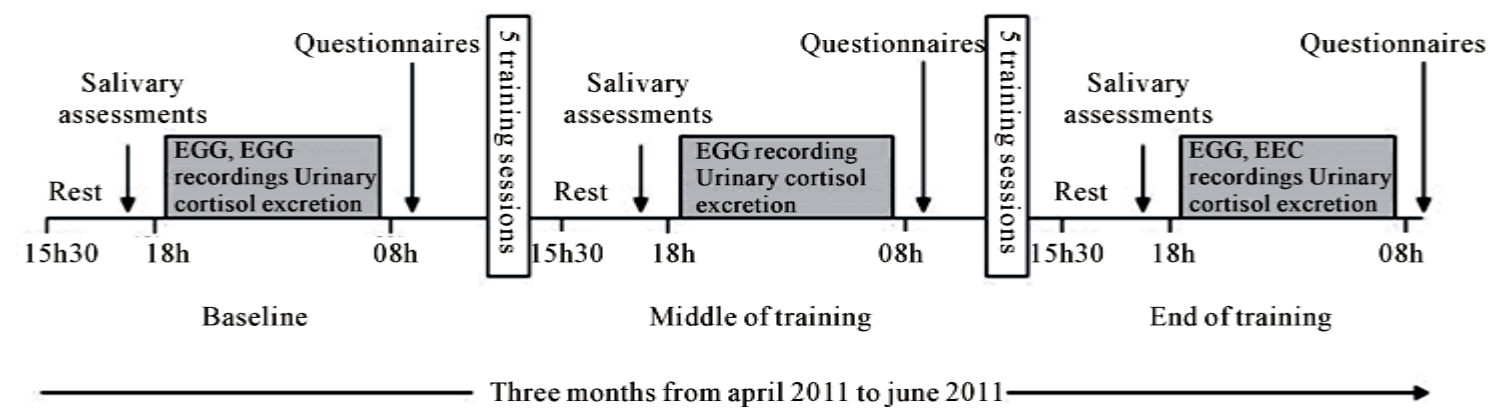

Figure 1.

The protocol design for the baseline, middle and end of the training time points. For the middle of the training time point, EEG was not recorded and salivary alpha amylase was not collected.

latory requirements, including the 1996 version of the Helsinki Declaration, and approved by the French Health Authorities. Nine volunteers had given written consent to participate in the study.

\section{Materials}

Psychological Assessments

All subjects completed a set of "paper and pencil" standardized assessments including common socio-demographic data, trait and state anxiety levels, the Cohen perceived stress scale, the Buguet Sleep questionnaire, and the Activation-Deactivation Adjective Check List. The Socio-demographic and traitanxiety questionnaire were only completed at the baseline timepoint whereas the four other questionnaires were completed at three time-points: a pre-intervention step (baseline), a middle intervention step and an after the end of the intervention step.

Trait and state anxiety was assessed using the French version of the Spielberger State-Trait-Anxiety Inventory (S-STAI). It is a 40-item self-reported questionnaire (Spielberger, 1970, 1975; Bruchon-Schweitzer \& Paulhan, 1993; $10 \mathrm{~min})$. The internal consistency of the whole scale was very good (Cronbach's alpha $=.80$ to .92; Bruchon-Schweitzer \& Paulhan, 1993). In the state portion of the scale, 20 items ask subjects to report the extent of their anxiety at particular moments. In the trait scale, the remaining 20 items ask respondents to indicate the intensity of their anxiety in general. Mean (SD) in a non-clinical sample of middle-aged men were 35.55 (9.76) and 36.54 (10.22) for trait and state anxiety, respectively.

The Perceived Stress Scale (PSS; 5 min; Bruchon-Schweitzer, 2002; Cercle et al., 2008; Cohen et al., 1983) is a 14-item selfreported scale designed to assess subjects' appraisal of how stressful their life situation feels to them. The Cronbach's alpha reliability estimate for this measure was .84 (Bruchon-Schweitzer, 2002; Cohen et al., 1983). The PSS is recommended for assessing non-specific appraisals because it is found to predict better stress-related psychological symptoms and physical symptoms compared to commonly used life event scales (Berghal \& Berghal, 2002).

A subjective self-reported sleep questionnaire (5 min; Buguet et al., 1981; Trousselard et al., 2009) was used to evaluate the quality of the subjects' sleep during the week before each session. It consisted of two sleep items [i.e., restoration quality and ease of falling asleep) featured by Visual Analogue Scales from “-”on the left to “+” on the right. Three well-being items investigated physical, psychological mood and Joy of going to work. The subjects "hooked" a cross on a scale using the pencil, and dragged it to the appropriate location on the scale $(12 \mathrm{~cm}$ long). This questionnaire was filled on awakening during one week at each of the steps of the evaluation sessions, leading to 7 daily questionnaires per time-point for each subject.

The Activation-Deactivation Adjective Check List (AD-ACL, Thayer, 1979, 1989) is a multidimensional self-reported test assessing various transitory arousal states. The 20 item-short form evolved two bipolar dimensions titled Energetic-Arousal and Tense-Arousal (Thayer, 1967, 1978, 1986, 1989; Thayer et al., 1994). Energetic-Arousal contains both energy and sleep items leading to General Activation (GA) and tiredness (Deactivation-Sleep, DS) sub-factors. The tense-arousal contains both emotional and quiet items leading to Tension (High Activation, HA) and calmness (General-Deactivation, GD) sub-factors. The reliability of the AD-ACL scale was estimated as .92 based on communality results from a factor analysis (Thayer, 1978).

\section{Physiological and Sleep Assessments}

Physiological recordings used two Actiwave devices (Actiwave, Camntech Ltd.). They are a range of miniature solid-state biosignal recorders which can be worn discreetly on the body without the need for a large belt mounted recorder or lengthy wires. They are reliable and record the same thing as existing ECG/EEG/EOG/EMG capturing equipment under normal sleep laboratory conditions (Elbaz et al., 2008). For one subject, electrodes were placed at about $18 \mathrm{~h} 00$, correct signal functioning were controlled with a calibration procedure, and then the recordings were programmed to record at $22 \mathrm{~h} 00$, when the subject goes to bed. After the night at home, he returned to the lab at around $8 \mathrm{~h} 00$ the following morning and the devices were removed to analyse the night's recordings. Assessments were applied at the baseline, and at the end of the training leading to 18 EEG and 18 HRV recordings.

An Actiwave Cardio was used for electrocardiogram recording. It was digitalized with a $256-\mathrm{Hz}$ sampling rate to accurately detect R-wave peaks. Time intervals from ectopic beats were detected and substituted by interpolated values of normal RR intervals using an adaptive filtering method (available on: http://tocsy.agnld.unipotsdam.de/) (Wessel et al., 1990). Beat-to-beat time series (HRV signal) were analysed by a produced and validated computer program (Niskanen, 2004). Readings were done by an HRV analysis expert who had no inclusion in the participants' experimental sessions. All HRV parameters were defined according to international measurements standards (Malik et al., 1996). The HRV temporal analy- 
sis of the night was carried out as requested for long recordings, namely sleep (Burr, 2007). The following time-domain HRV parameters were analysed: mean $\mathrm{NN}$ interval (mean $\mathrm{NN}$ ), standard deviation of the NN intervals (SDNN), standard deviation of the successive NN differences (SDSD), the square root of the mean of the sum of successive NN differences (RMSSD), and the percentage of adjacent pairs of RR intervals that differed by more than $50 \mathrm{~ms}$ from each other (pNN50). SDNN is indicative of overall HRV. SDSD, RMSSD and pNN50 evaluate beat-tobeat fluctuations. Although all the indexes are influenced by both sympathetic and parasympathetic activity, those extracted from beat-to-beat variability are considered good estimators of parasympathetic modulation of heart rate (Parati et al., 2006; Sollers et al., 2007), whereas the variable expressing long term HRV (SDNN) is dually influenced by cholinergic and adrenergic activities, as well as by other physiological inputs (Malik et al., 1996). Calculations were done for the entire night's study (from $2300 \mathrm{~h}$ to $0600 \mathrm{~h}$ ).

Another Actiwave module was used for the EEG recording. It was digitalized with a $128 \mathrm{~Hz}$ sampling. Reference record- ings were made using Compumedics Siesta/ProFusion equipment to record EEG, EOG and EMG channels and these were used to annotate sleep stages. EEG signals for "C3-A2" and "O1-A2" were recorded using two channels of the Actiwave EEG channel device, the chin EMG signal was recorded using two EMG channels, and the EOG was recorded using one channel. The EEG and EMG electrodes for the Actiwaves and reference systems were placed as close together as possible without connecting them together. In addition to the standard manual AASM scoring and resulting hypnograms, automated spectral analysis was used to quantify the power of each frequency band in 15-minute epochs. The EEG signals were also analysed for their spectral content in the Delta, Theta, Alpha and Beta bands during each sleep epoch by a computer program produced and validated [Somnologica].

\section{Endocrine Assessments}

All endocrine assessments concerning salivary enzyme alpha-amylase and salivary chromogranin A were carried out between $15 \mathrm{~h} 30$ and $18 \mathrm{~h} 00$ in order to control circadian variation (Branderger, 1992; Den, 2007). Salivary chromogranin A was collected at the baseline, middle-training and at the end of the training leading to 27 samples from the nine subjects. Salivary chromogranin A is a major protein in adrenal chromaffin cells and adrenargic sensitive neurons and a substantial index for psychosomatic stress (Nakane, 1998). Salivary enzyme alpha-amylase was collected at the baseline and at the end of the training leading to 18 samples from the nine subjects. Salivary enzyme alpha-amylase is reported to have a reaction to psychological stressors (Nater et al., 2005; Nater et al., 2006). For each endocrine measure, a $5 \mathrm{~mL}$ saliva sample was collected in Salivette tubes according to specification of the provider [Yanaihara Inst Inc and Salimetrics; Europe ltd., respecttively]. Two hours before each collection, eating, drinking or smoking were not allowed. Once filled, the tubes were centrifuged, sampled into $1.5 \mathrm{~mL}$ aliquots stored at $-80^{\circ} \mathrm{C}$ until analysis. Salivary concentrations were analyzed using the enzymelink immunoabsorbant assay kits (ELISA; Kit Yanaihara Inst Inc YK 070 and Kit Salimetrics 1-1902 respectively for the chromogranin A and the alpha amylase). All samples were analyzed in duplicate.
A 12h-night-cortisol excretion was assessed and collected at the baseline, middle-training and at the end of the training. Cortisol concentrations were measured using radioimmunoassay kits according to the protein concentration rates (Siemens Healthcare Diagnostics, Germany). The urinary cortisol excretion rates were calculated according to the diuresis and the creatinine excretion rates. All samples were analyzed in duplicate.

\section{Procedure}

The intervention program, so called Cardiac Coherence Training (CCT), was derived from the "Power to Change Performance program” developed by Institute of HeartMath (Boulder Creek, CA). More detailed descriptions of the techniques, their conceptual basis, and their applications in organizational settings can be found elsewhere (Childre \& Cryer, 2000; Childre \& Martin, 1999; Childre \& Rozman, 2005). For the study, the adapted program was centered on helping subjects to deal with stress faced with job insecurity and work organisational restructuring strains. It consisted of ten individual sessions of one hour each week for a three-month duration, and daily regular exercises of few minutes. The full program contained three modules whose progression was adjusted according to individual progression.

1) Risk factors: what they are, how to interpret them, and how they relate to health and wellness.

2) Freeze-Frame: Freeze-Frame is a positive emotion refocusing technique specifically designed to improve decisionmaking, especially in stressful or challenging situations. The technique is intended to enable individuals to intervene more effectively when a stress reaction is triggered, and with practice, to offset the harmful or depleting physiological aspects of the stress response. In essence, the technique enables people to consciously disengage from draining negative mental and emotional reactions as they occur and to activate a neutral or positive emotional state before returning to address the stressor from a more emotionally balanced perspective.

3) Power tools for inner quality: creating a caring culture and increasing job satisfaction. The Power to Change Performance intervention is based on the theory that the cumulative effect of many employees self-regulating emotions more effectively and communicating with each other in a more constructive and caring fashion will bring about a positive change in the surrounding organizational culture within which employees work. This program module includes the following tools: the Heart Lock-In technique-an emotional restructuring exercise designed to reduce stress and increase psychophysiological coherence; Appreciation-taking time out in one's day to notice and be grateful for the positive aspects of one's life; and Neutral learning to neutralize distressing emotions.

\section{Statistical Analyses}

All data, expressed as mean (SD), were treated as ordinal data except for educational levels, tobacco use and marital status. The effect of the CCT was performed using separate analyses of variance (ANOVA) with time-points (baseline, middle-training and after the training) as within-subjects effect, except for the EEG measures only recorded at the baseline and post-training time-points, and the salivary alpha amylase only collected at the baseline and post-training time-points. For significant interaction between within- and between-subjects, 
post-hoc analyses using Newman-Keuls were applied. Furthermore, in order to evaluate the links between the psychological effects and endocrine effects separately, a delta value (end of the training minus baseline value) expressed in \% of change was calculated for each variable. All comparisons between groups, according to the anxiety-trait level, were assessed using nonparametric tests, due to the small size of the groups.

All analyses were performed with SPSS 17.0 for Windows (SPSS GmbH Software, Munich). We judged $p<0.05$ as significant. When $p \leq 0.1$, results were expressed as a tendency to a difference.

\section{Results}

\section{Socio-Demographic Description}

The mean age of the nine male respondents was 39.77 (6.45) years with $7.9 \pm 1.9$ years of education above grade $7.44 .44 \%$ were married. $33.33 \%$ were smokers. All subjects, except two (22.22\%), practiced sport regularly. None had any coaching practice or a stress management program. Mean trait-anxiety was 35.55 (9.08) with four subjects above the mean trait-anxiety level (44.44\%), the remaining above this mean cut-off. The subjects' adhesion to the protocol was good as all maintained their participation for the complete duration of the study and no training session absence was noted.

\section{Effects of the Stress Training on Psychological Assessments}

For the state-anxiety assessment, the ANOVA showed no difference between the three time-points $(\mathrm{F}(2.8)=0.33, p=$ 0.723).

The ANOVA performed between the three steps on the perceived stress showed a significant decrease on the score after the training $(F(2.8)=8.12, p=0.01)$. The post-hoc analysis showed that the successful transformation was observed between baseline and both the middle- and end-steps' assessments.

The ANOVA performed between the three steps on the sleep EVA variables showed a significant increase on the sleep restoration score quality after the training $(\mathrm{F}(2.8)=6.32, p=0.01)$. This was associated with an increase in the facility of falling asleep $(\mathrm{F}(2.8)=4.54, p=0.04)$. The post-hoc analysis showed that the successful transformations were observed between the baseline and end-steps assessments.

Concerning the well-being items of the sleep questionnaire investigating physical, psychological well-being (mood and joy of going to work), the separate ANOVA showed that the scores increased for the physical score $(F(2.8)=7.89, p=0.01)$. The post-hoc analysis showed that the successful transformation was observed between baseline and the end-steps assessments. Tendencies were observed for the mood well-being $(\mathrm{F}(2.8)=$ $3.21, p=0.08)$ and the joy of going to work $(\mathrm{F}(2.8)=3.54, p=$ $0.06)$.

For the AD-ACL questionnaire, the ANOVAs performed between the three steps on each sub-factor highlighted a significant increase of the General Activation scores $(F(2.8)=6.85$, $p=0.01)$. The post-hoc analysis showed that the successful transformation was observed between the baseline and both middle- and end-steps' assessments.

\section{Effects of Stress Training on the Physiological}

\section{Assessments}

The ANOVA that was performed between the three steps on the SDNN showed a tendency to decrease between the time points. No difference was found for the RMSSD, as for all other ECG parameters (Table 1).

Table 2 shows the recorded sleep parameters and separate ANOVAs applied to the parameters between the baseline and the end of the training time-points. Results only showed a significant increase of the time in REM as a \% of sleep time. The number of REM periods did not change between the two timepoints $(\mathrm{t}(1.8)=0.22, p=0.82)$ with $4(1.29)$ and 3.86(1.26) mean number of REM periods during the recorded night, for the baseline and the end of the training time-points respectively. There was a tendency to a significant increase of the duration of REM period at the end of the training compared to the duration of REM period at the baseline was observed for the fourth REM period of the night $((\mathrm{t}(1.8)=2.15, p=0.06$; Figure 2$)$.

\section{Effects of the Stress Training on the Endocrine Assessments (Figure 3)}

The ANOVA performed between the three steps on the salivary enzyme alpha-amylase concentration showed a significant decrease in concentration after the training $(\mathrm{F}(2.8)=5.89, p=$ $0.04)$. The post-hoc analysis showed that the successful transformation was observed between the baseline and both the middle- and end-steps assessments.

The ANOVA performed between the two steps on the salivary chromogranin A showed a tendency to a decrease in concentration of the salivary enzyme alpha amylase after the training $(\mathrm{F}(2.8)=2.79, p=0.08)$.

For the urinary cortisol excretion, the ANOVA performed between the three steps showed no difference between timepoints $(\mathrm{F}(2.8)=3.24, p=0.16)$.

\section{Impact of the Anxiety-Trait Level on the Effects of the Intervention}

According to Spielberger's norms (Spielberger, Gorsuch, Lushene, Vagg, \& Jacobs, 1983), the four subjects scoring higher than the mean score were defined has the high traitanxiety group (GHTA), and the five subjects scoring lower than the mean score were defined as the high trait-anxiety group (GLTA). Trait-anxiety scores differed between group $(\mathrm{H}(1.9)=$ $6.05, p=.013)$. No significant difference for age $(\mathrm{H}(1.9)=$ $0.288, p=.591)$, educational level $(\mathrm{H}(1 . \mathrm{N}=9)=0.388, p=$ $0.491)$, for matrimonial status $\left(X^{2}=4, p=0.857\right)$ same for the tobacco users $\left(X^{2}=3.5, p=0.899\right)$ factors were observed between the GHTA and the GLTA.

Table 3 depicted differences in baseline assessments between the two groups. The GHTA was higher in salivary chromogranin A concentration, perceived stress score compared to the GLTA. It also tended to be higher in the state-anxiety score and the RMSS value. This was associated with a lower score in the subjective sleep restoration quality, the joy of going to work, the Energetic-Arousal General Activation, and the \% of time in REM compared to the GLTA. Moreover, a tendency of a lower efficiency in reference to sleep time was observed. In line with such a pattern of baseline functioning, the GHTA differed from the GLTA in the effects of the training (Table 4): For the GHTA, higher increases were observed after the training for the 
M. TROUSSELARD ET AL.

Table 1.

Effects of the stress training on the HRV assessments according to the time-points.

\begin{tabular}{|c|c|c|c|c|c|c|c|}
\hline Variables & Time-point & Mean & Minimum & Maximum & Standard-deviation & $\mathbf{F}$ & $p$ \\
\hline & Baseline & 1025.24 & 931.13 & 1133.26 & 77.61 & & \\
\hline \multirow[t]{3}{*}{ Mean NN interval (ms) } & Middle & 1031.74 & 738.26 & 1299.00 & 180.31 & 1.23 & 0.88 \\
\hline & After & 1037.25 & 870.32 & 1190.18 & 112.14 & & \\
\hline & Baseline & 132.16 & 61.7 & 272.60 & 70.47 & & \\
\hline \multirow[t]{3}{*}{ SDNN } & Middle & 113.42 & 60.70 & 205.40 & 51.46 & 3.25 & 0.08 \\
\hline & After & 90.73 & 34.46 & 136.35 & 40.14 & & \\
\hline & Baseline & 47.64 & 22.20 & 66.83 & 16.82 & & \\
\hline \multirow[t]{3}{*}{ SDSS } & Middle & 66.48 & 22.20 & 145.64 & 44.61 & 1.14 & 0.40 \\
\hline & After & 52.45 & 11.28 & 76.73 & 22.48 & & \\
\hline & Baseline & 29.58 & 6.34 & 50.33 & 19.19 & & \\
\hline \multirow[t]{3}{*}{ pNN50 } & Middle & 27.96 & 4.76 & 55.06 & 21.10 & 0.89 & 0.41 \\
\hline & After & 34.66 & 0.52 & 62.87 & 24.32 & & \\
\hline & Baseline & 94.47 & 28.73 & 211.30 & 57.58 & & \\
\hline \multirow[t]{2}{*}{ RMSS } & Middle & 98.76 & 28.73 & 229.30 & 66.73 & 1.67 & 0.23 \\
\hline & After & 70.60 & 15.39 & 113.84 & 34.52 & & \\
\hline
\end{tabular}

Table 2.

Effects of the stress training on the sleep assessments according to the time-points.

\begin{tabular}{|c|c|c|c|c|c|c|c|}
\hline Variables & Time-point & Mean & Minimum & Maximum & Standard-deviation & $\mathbf{F}$ & $p$ \\
\hline \multirow{2}{*}{ Number of arousals: } & Baseline & 16.57 & 3.00 & 31.00 & 8.99 & \multirow{2}{*}{0.19} & \multirow{2}{*}{0.67} \\
\hline & After & 15.62 & 6.00 & 31.00 & 9.19 & & \\
\hline \multirow{2}{*}{ Total time analyzed: } & Baseline & 431.07 & 340.00 & 564.00 & 75.64 & \multirow{2}{*}{0.024} & \multirow{2}{*}{0.88} \\
\hline & After & 446.81 & 319.50 & 491.50 & 55.73 & & \\
\hline \multirow{2}{*}{ Sleep Period: } & Baseline & 425.71 & 337.50 & 558.50 & 76.26 & \multirow{2}{*}{0.027} & \multirow{2}{*}{0.87} \\
\hline & After & 442.06 & 318.50 & 489.00 & 54.11 & & \\
\hline \multirow{2}{*}{ Wake time during sleep period: } & Baseline & 34.85 & 23.00 & 52.50 & 10.73 & \multirow{2}{*}{1.65} & \multirow{2}{*}{0.26} \\
\hline & After & 49.06 & 5.00 & 144.50 & 44.36 & & \\
\hline \multirow{2}{*}{ Total sleep time: } & Baseline & 390.85 & 304.00 & 531.50 & 75.55 & \multirow{2}{*}{0.02} & \multirow{2}{*}{0.89} \\
\hline & After & 392.87 & 293.50 & 468.50 & 55.70 & & \\
\hline \multirow{2}{*}{$\begin{array}{l}\text { Sleep latency in first } 60 \text { seconds } \\
\text { of sleep: }\end{array}$} & Baseline & 5.35 & 2.50 & 9.00 & 2.68 & \multirow{2}{*}{0.033} & \multirow{2}{*}{0.86} \\
\hline & After & 4.75 & 0.00 & 18.50 & 5.94 & & \\
\hline \multirow{2}{*}{$\begin{array}{l}\text { Sleep efficiency referred to sleep } \\
\text { period: }\end{array}$} & Baseline & 0.91 & 0.88 & 0.95 & 0.020 & \multirow{2}{*}{1.66} & \multirow{2}{*}{0.26} \\
\hline & After & 0.93 & 0.75 & 0.98 & 0.08 & & \\
\hline \multirow{2}{*}{$\begin{array}{l}\text { Time in REM \% of total sleep } \\
\text { time: }\end{array}$} & Baseline & 0.17 & 0.14 & 0.23 & 0.03 & \multirow{2}{*}{24.18} & \multirow{2}{*}{0.001} \\
\hline & After & 0.20 & 0.16 & 0.25 & 0.02 & & \\
\hline \multirow{2}{*}{$\begin{array}{c}\text { Time in S1 \% of total sleep } \\
\text { time: }\end{array}$} & Baseline & 0.06 & 0.02 & 0.10 & 0.02 & \multirow{2}{*}{1.21} & \multirow{2}{*}{0.32} \\
\hline & After & 0.05 & 0.01 & 0.09 & 0.03 & & \\
\hline \multirow{2}{*}{$\begin{array}{c}\text { Time in S2 a \% of total sleep } \\
\text { time: }\end{array}$} & Baseline & 0.42 & 0.35 & 0.53 & 0.07 & \multirow{2}{*}{0.75} & \multirow{2}{*}{0.42} \\
\hline & After & 0.40 & 0.27 & 0.51 & 0.07 & & \\
\hline \multirow{2}{*}{$\begin{array}{c}\text { Time in S3 \% of total sleep } \\
\text { time: }\end{array}$} & Baseline & 0.32 & 0.20 & 0.45 & 0.09 & \multirow{2}{*}{0.15} & \multirow{2}{*}{0.71} \\
\hline & After & 0.31 & 0.13 & 0.53 & 0.12 & & \\
\hline
\end{tabular}


M. TROUSSELARD ET AL.

Table 3.

Comparisons between groups according to the trait-anxiety scores for the psychological, physiological and endocrine variables.

\begin{tabular}{|c|c|c|c|c|c|c|}
\hline & Variables & Group & Mean & SD & $\mathrm{X}^{2}$ values & $p$ \\
\hline \multirow{6}{*}{ Endocrine } & \multirow{2}{*}{$\begin{array}{l}\text { Salivary ChromograninA } \\
(\mathrm{pm} / \mathrm{ml})\end{array}$} & GLTA & 3.41 & 2.30 & \multirow{2}{*}{4.86} & \multirow{2}{*}{0.027} \\
\hline & & GHTA & 18.83 & 12.09 & & \\
\hline & \multirow{2}{*}{ Salivary Amylase (U/ml) } & GLTA & 98.4 & 44.86 & \multirow{2}{*}{0.06} & \multirow{2}{*}{0.806} \\
\hline & & GHTA & 117.83 & 48.25 & & \\
\hline & \multirow{2}{*}{$\begin{array}{l}\text { Urinary cortisol excretion } \\
(\mathrm{nM} / \mathrm{L})\end{array}$} & GLTA & 120.06 & 51.08 & \multirow{2}{*}{0.96} & \multirow{2}{*}{0.327} \\
\hline & & GHTA & 106.19 & 24.73 & & \\
\hline & \multirow{2}{*}{ State-anxiety } & GLTA & 27.2 & 6.76 & \multirow{2}{*}{2.57} & \multirow{2}{*}{0.10} \\
\hline & & GHTA & 41.37 & 10.25 & & \\
\hline & \multirow{2}{*}{ Perceived stress } & GLTA & 36.00 & 3.93 & \multirow{2}{*}{4.90} & \multirow{2}{*}{0.026} \\
\hline & & GHTA & 44.75 & 4.5 & & \\
\hline & \multirow{2}{*}{ Sleep restoration quality } & GLTA & 5.72 & 0.85 & \multirow{2}{*}{6} & \multirow{2}{*}{0.014} \\
\hline & & GHTA & 3.90 & 0.41 & & \\
\hline & \multirow{2}{*}{ Easiness to go to sleep } & GLTA & 5.73 & 1.15 & \multirow{2}{*}{2.16} & \multirow{2}{*}{0.141} \\
\hline & & GHTA & 4.33 & 0.17 & & \\
\hline & \multirow{2}{*}{ Joy of going to work } & GLTA & 5.92 & 0.52 & \multirow{2}{*}{6} & \multirow{2}{*}{0.014} \\
\hline & & GHTA & 3.84 & 0.70 & & \\
\hline \multirow{12}{*}{ Psychological } & \multirow{2}{*}{ Mood well-being } & GLTA & 6.32 & 0.48 & & \\
\hline & & GHTA & 3.83 & 0.74 & 6.2 & 0.013 \\
\hline & Phwcical wull haing & GLTA & 6.00 & 0.57 & 63 & 0012 \\
\hline & Pnysical went-deng & GHTA & 3.86 & 0.41 & 0.3 & 0.013 \\
\hline & Conol A A tivotion & GLTA & 12.16 & 2.17 & & \\
\hline & General Activation & GHTA & 7.77 & 2.48 & 4.86 & 0.027 \\
\hline & Doactivation Slon & GLTA & 10.1 & 1.92 & 054 & 0467 \\
\hline & Deactivatuon-sleep & GHTA & 8.3 & 3.08 & 0.54 & 0.402 \\
\hline & High Activation & GLTA & 4.72 & 0.70 & 006 & 0805 \\
\hline & & GHTA & 5.97 & 3.01 & & \\
\hline & & GLTA & 13.86 & 1.96 & 6 & \\
\hline & General Deactivation & GHTA & 8.35 & 3.01 & 6 & 0.14 \\
\hline & Sleep efficiency referred to sleep & GLTA & 0.92 & 0.02 & 309 & 007 \\
\hline & period & GHTA & 0.89 & 0.01 & & \\
\hline & Time in REM \% of total sleep & GLTA & 0.18 & 0.03 & 375 & 0052 \\
\hline Pbyciolorical & time: & GHTA & 0.14 & 0.01 & 0.15 & 0.052 \\
\hline Pnysioiogical & SDNN & GLTA & 103.66 & 48.44 & 10 & 0170 \\
\hline & SDINIV & GHTA & 179.66 & 85.28 & 1.8 & $0.1 / 9$ \\
\hline & RMSSD & GLTA & 72.91 & 42.38 & 268 & 0101 \\
\hline & RMSSD & GHTA & 130.41 & 70.11 & 2.68 & 0.101 \\
\hline
\end{tabular}

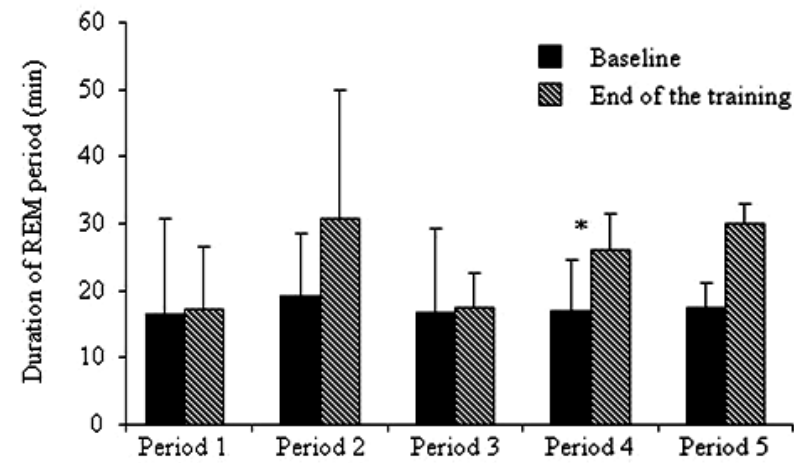

Figure 2.

Effects of the stress training on the duration of REM periods. "Indicating a tendency to a difference $(p \leq 0.1)$. For one subject with six REM periods at baseline, the last one was not represented here. mood well-being, and the time in REM as a \% of sleep time and greater decreases were found in the salivary chromogranin A concentration, the Energetic-Arousal Deactivation-Sleep and the Tense-Arousal High Activation.

\section{Discussion}

The aim of the present study concerned the evaluation of the benefits of the use of an intervention based on physiological coherence (CCT) in a sample of middle-aged workers confronted to organisational changes. First, it must be noted a high adhesion of the subjects to the experimental study: The intervention program was conducted completely, miniature biosignal recordings were well accepted without complaint or pain during the home-night of the assessments.

Concerning the effects of the CCT on stress and well-being, results showed fast successful effects after the intervention. The 

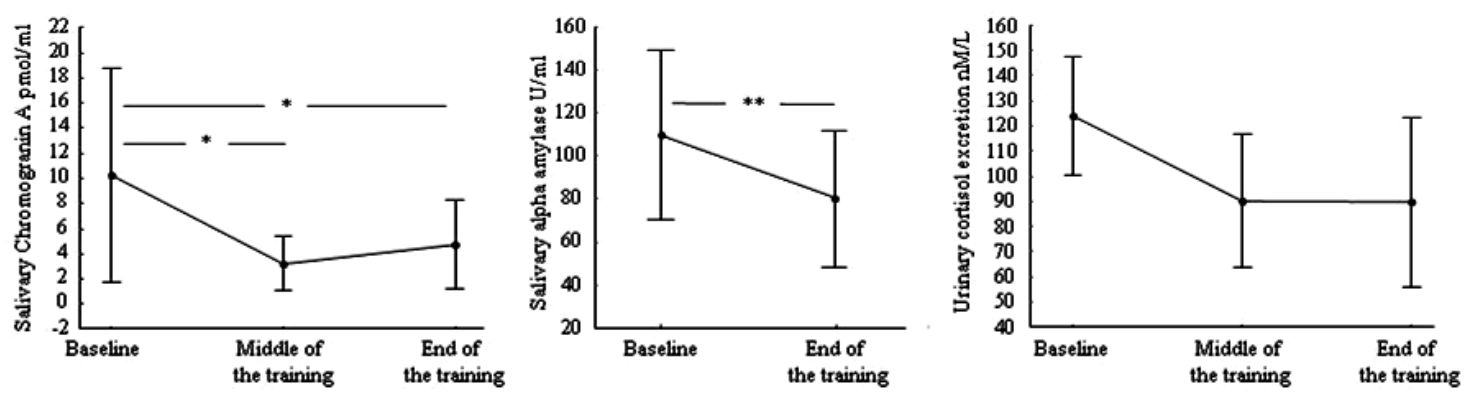

Figure 3.

Effects of the stress training on the endocrine assessments. "Indicating a tendency to a difference $(\mathrm{p} \leq 0.1)$ and ${ }^{* *}$ indicating a significant difference $(\mathrm{p}<0.05)$.

Table 4.

Comparisons between groups according to the trait-anxiety score for the \% of changes in the psychological, physiological and endocrine variables.

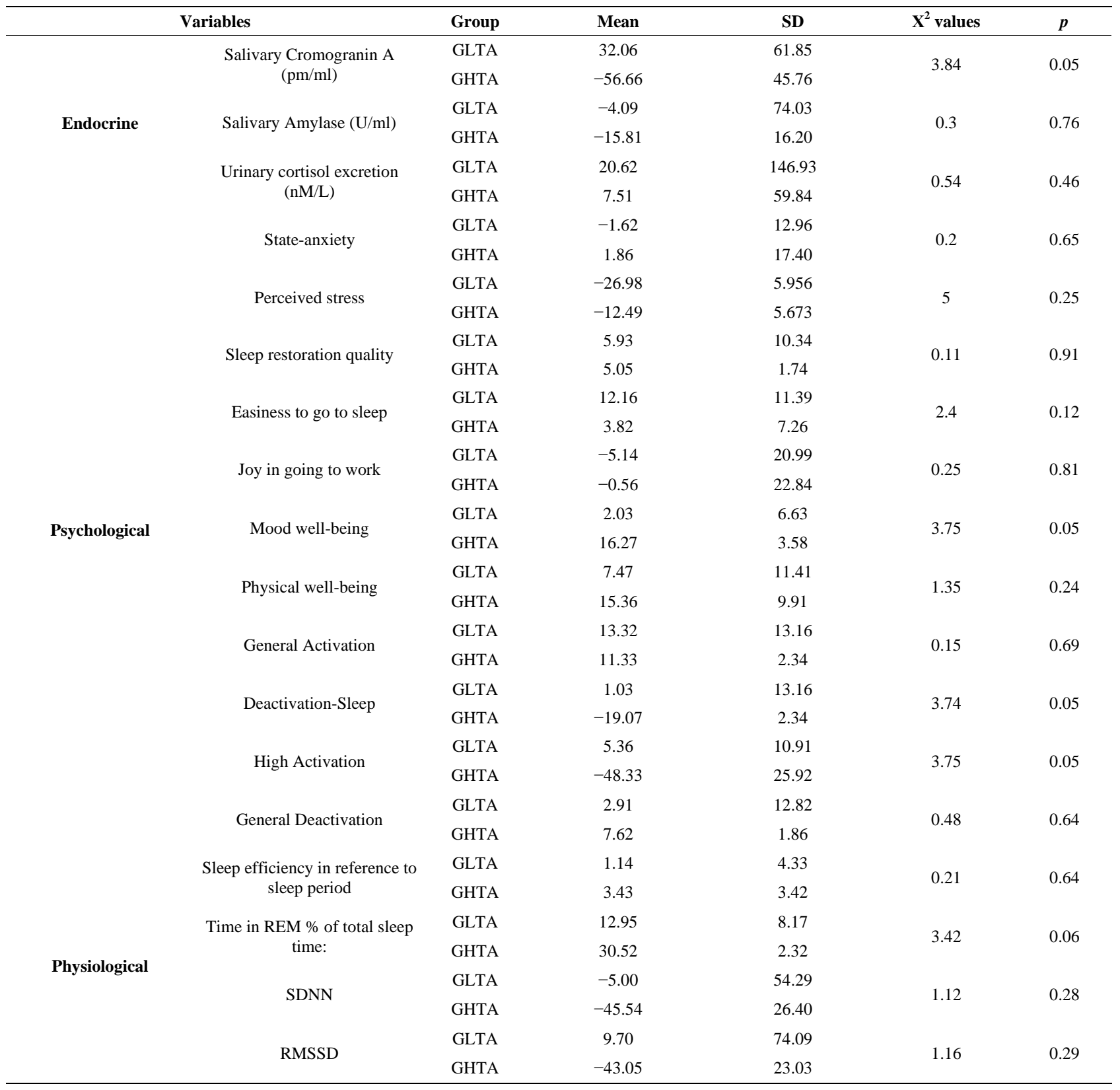


decrease in the perceived stress was associated with a subjecttive benefit for the physique well-being and tendencies of the increases in the subjective psychological well-being and a joy of going to work. General Activation also increased after the intervention. The AD-ACL, according to Thayer's theory (Thayer, 1987), contains related dimensions with the theoretical assumption that a danger phenomenon has a greater psychological impact (greater tense arousal) when energy (General Activation) is low, and a lesser impact when energetic arousal is high. All together, these results indicated successful transformations after the intervention for the subjective daily life outcomes.

Furthermore, endocrine improvements were found in the ANS functioning as suggested by the observed changes in the salivary alpha amylase and chromogranin A concentrations after the intervention. In accordance, the night sympathetic activity decreased after the intervention. However, this improvement towards a lower sympathetic activity was not associated with an improvement of the HPA axis functioning.

Concerning the effects of the intervention on subjective sleep quality, results found both a subjective improvement of the quality of sleep associated with an increase in the facility to fall asleep. Moreover, objective assessments showed an increase in REM time referred to the \% of sleep. Human data from literature are abundant about stress effects on sleep changes for nonclinical subjects. Summing up the main data in humans, REM sleep increased several days after the subjects had been exposed to intensely demanding and stressful events (Cartwright \& Wood, 1991; Sushecki et al., 2009). These REM rebounds are understood as an important adaptive behaviour for recovery following a stressful situation (Sushecki et al., 2009). Researchers also found that subjects who were deprived of REM sleep had trouble learning. It's considered that if we don't get enough of it we may experience serious negative physical and psychological changes (Sushecki et al., 2009; Vgontzas et al., 2000). This may be considered as the body's "Yellow Alert" response to REM Sleep Deficit. It is a compensatory increase in the percentage of sleep time devoted to REM sleep. Indeed, after a period of deprivation, REM sleep can increase by $40 \%$ for several days before returning to a normal level (Riemann et al., 2001; Suchecki et al., 2009). Chronic stress has been claimed to be one of the triggering factors of emotional-related sleep disorders, such as insomnia, depressive- and anxietydisorders. Thus, data from chronic stress comes from clinical sample, namely depression or post-traumatic stress disorder and showed that duration and repartition of REM were impaired (Suchecki et al., 2009). More than $80 \%$ of slow wave sleep is concentrated in the first half of the typical 8-h night, whereas the second half of the night contains roughly twice as much REM sleep as does the first half. For these clinical individuals, time in REM was usually decreased with REM periods mainly observed during the first part of the night (Suchecki et al., 2009). Although the functional association between emotional memory and REM-sleep electrophysiology remains unclear, the role of REM-sleep was highlighted for both the regulation and the consolidation of emotional human memories, findings that have direct translational implications for affective psychiatric and mood disorders (Nishida, 2008).

To our knowledge, less is known about how stress management intervention deals with sleep for non-clinical individuals. Referred to the role of REM-sleep for the regulation of emotional human memories, the increase of REM time observed after the stress management intervention, namely in the last part of the night, suggests that the intervention mainly based on emotional management may directly impact emotional memories during the night (Gais \& Born, 2004; Plihal \& Born, 1999). The decrease in sympathetic activity during the night was in accordance with the data showing that REM sleep occurs when activity in the aminergic system has decreased enough to allow the reticular system to escape its inhibitory influence (Hobson et al., 1975, 1998; Payne \& Nadel, 2004). Referring to our results, such a pattern appears to help subjects recover to cope more efficiently with the daily stressful concerns of work. Finally, all the observed biopsychophysiological changes after the intervention indicate a clear and rapid benefit of such a program for subjects confronted with chronic stress due to downsizing and organisational restructuring. In terms of allostasis, the program appears to improve the process of achieving homeostasis through physiological and behavioural changes faced with perceived and/or anticipated demand.

Considering the question of the inter-variability in monitoring stressors, the baseline, like the outcomes, are dependent on individual trait-anxiety levels. A clear opposite biopsychophysiological pattern was observed in the baseline data between high and low levels of trait-anxiety. The subjects scoring high on the trait-anxiety scale exhibited subjective stress, subjective as objective impairment in sleep, low well-being outcomes, low Energetic-Arousal General Activation, and Sympathetic Nervous System (SNS) imbalance (high chromogranin A concentration associated with a tendency to a higher night-time parasympathetic activity). Effects of the intervention program also differed: compared to subjects low in trait-anxiety, subjects prone to higher trait-anxiety exhibited higher increases after the training for well-being outcomes, and time in REM as a \% of sleep time, and higher decreases for subjective stress, and the SNS activation. Furthermore, based on the observation of selfratings of energy and tension at various time of days, Thayer's theory considered that arousal state modulates mood facing personal problems: for example a mood pattern of low energy and high tension predicts more negative problem perceptions, such as worries and rumination, than a pattern of high energy and low tension (Thayer, 1987, 1989). In accordance with such an explanation, a logical pattern of successful transformations after the intervention program can be considered for subjects with high trait-anxiety: the decrease in Deactivation-Sleep, that is a low Energetic-Arousal, was associated with a decrease in High Activation, that is a low Tense-Arousal, and an increase in well-being outcomes. Faced with an observed decrease in sympathetic activity, and the increase in REM-sleep, one of the major issues, however, concerns causality between the psychological improvements, the changes in energetic arousal, the decrease in salivary chromogranin A concentration and the increase in REM-sleep time.

Whether the observations may indicate that stress programs are all the more effective than anxious subjects, they also confer more complexity to the stress-sleep relationship. Stress and sleep appear related to each other in a bidirectional way. If on the one hand poor or inadequate sleep should exacerbate emotional, behavioural and stress-related responses when traitanxiety is high, on the other hand stress reduction should induce sleep rebound, most likely as a form to cope with the adverse stimuli when trait-anxiety is high. Whether it is considered that increased sleep, especially the REM phase, following a stressful situation is an important adaptive behaviour for re- 
covery, this endogenous advantage appears to be impaired in human beings that exhibit high levels of anxiety and anxietylike behaviour (Mellman \& Uhde, 1989; Reynolds et al., 1983; Spoormaker \& van den Bout, 2005). Our data completed this knowledge by highlighting that these subjects notably improved with an adapted stress management program and that the successful transformations linked to an increase in REM-sleep and a decrease in emotional disturbances. The most important point that the recent data highlighted is the impact of prolonged sleep disruption, namely REM-sleep reduction, may affect neurogenesis (Lucassen et al., 2010; Meerlo et al., 2009).

There were several limitations to this study that preclude firm conclusions. The first limitation is the sample's small size. Most notably, it can be assumed that this small size could account for the absence of a significant decrease in the urinary cortisol excretion after the intervention. Furthermore, given the number of statistical comparisons, the efficiency of the intervention program should be accepted with caution. Results, secondly, need further investigations, namely randomized controlled studies. The third limitation concerns the duration of the positive effects on the improvement of the outcomes, which were not assessed. Another limitation concerns the absence of data about dreams as recent studies clearly showed a relationship between dreams, REM and memory consolidation (Baylor \& Cavallero, 2001; Hobson et al., 1998; Payne \& Nadel, 2004). Finally, mechanisms were not evaluated in this study, thus relationships between emotional processing, sleep regulation, SNS balance and brain functioning before and after the intervention need to be further investigated.

\section{Conclusion}

To sum up, our findings showed that such an intervention approach appears to help subjects deal with stress faced with insecurity and contingent work arrangements. Moreover, it may appear to be more efficient when the subjects had a high level of trait-anxiety. Sleep functioning, namely REM-sleep, appears to be one of the main mechanisms of successful transformation. It is to our knowledge the first proof of concept in non-clinical samples of an ecological relationship between emotional stress recovery and REM sleep. Such are these findings, even if they need to be investigated further, may be considered as a potentially low cost effective approach to the care of individuals confronted with normal stress in their job. Finally, the importance must be highlighted, of miniature biosignal systems for recording objective parameters in daily life to lead to the opening up of ecological studies in psychophysiology.

\section{Competing Interest}

The authors declare that there are no competing interests

\section{Acknowledgements}

This study is part of an ongoing project on military psychology supported by the French 'Service de Santé des Armées'.

\section{REFERENCES}

Akerstedt, T., Knutsson, A., Westerholm, P., Theorell, T., Alfredsson, L., \& Kecklund, G. (2002). Sleep disturbances, work stress and work hours. Journal of Psychosomatic Research, 53, 741-748.

http://dx.doi.org/10.1016/S0022-3999(02)00333-1
Baylor, G. W., \& Cavallero, C. (2001). Memory sources associated with REM and NREM dream reports throughout the night: A new look at the data. Sleep, 24, 165.

Bergdahl, J., \& Bergdahl, M. (2002). Perceived stress in adults: Prevalence and association of depression, anxiety, and medication in Swedish population. Stress and Health, 18, 235-241. http://dx.doi.org/10.1002/smi.946

Bourbonnais, R., Brisson, C., Vezina, M., Masse, B., \& Blanchette, C. (2005). Psychosocial work environment and certified leave among nurses during organisational changes and downsizing. Rel Ind-Ind Rel, 60, 483-509.

Biondi, M., \& Picardi, A. (1999). Psychological stress and neuroendocrine function in humans: The last two decades of research. Psychotherapy and Psychosomatics, 68, 114-150. http://dx.doi.org/10.1159/000012323

Bolmont, B., \& Abraini, J. H. (2001). State-anxiety and low moods: Evidence for a single concept. Physiology \& Behavior, 74, 421-424. http://dx.doi.org/10.1016/S0031-9384(01)00575-3

Boyce, T., \& Ellis, B. (2005). Biological sensitivity to context: I. An evolutionary-developmental theory of the origins and functions of stress reactivity. Development and Psychopathology, 17, 271-301. http://dx.doi.org/10.1017/S0954579405050145

Brandberger, G. (1992). Endocrine ultradian rythms during sleep and wakefulness. In D. Lloyd, \& E. L. Rossi (Eds.), Ultradian rythms in life process (pp. 123-138). London: Springer Verlag.

Bruchon-Schweitzer, M. (2002). Psychologie de la santé: Modèles, concepts, et méthodes. Paris: Dunod.

Bruchon-Schweitzer, M., \& Paulhan, I. (1993). Inventaire d'Anxiété Trait-État. Forme Y. STAI-Y. Paris: Les Éditions du Centre de Psychologie Appliquée.

Buguet, A., Raphel, C., Bugat, R., \& Fourcade, J. (1981). Etats de vigilance en opération continue. International Review of the Army Navy Air Force Medicine Services, 54, 101-102.

Burr, R. L. (2007). Interpretation of normalized spectral heart rate variability indices in sleep research: A critical review. Sleep, 30.

Carlson, L. E., \& Garland, S. N. (2005). Impact of mindfulness-based stress reduction (MBSR) on sleep, mood, stress and fatigue symptoms in cancer outpatients. International Journal of Behavioral Medicine, 12, 278-285. http://dx.doi.org/10.1207/s15327558ijbm1204 9

Cartwright, R. D., \& Wood, E. (1991. Adjustment disorder of sleep: The sleep effects of a major stressful event and its resolution. Psychiatry Research, 39, 199-209.

http://dx.doi.org/10.1016/0165-1781(91)90088-7

Cerclé, A., Gadea, C., Hartmann, A., \& Lourel, M. (2008). Typological and factor analysis of the perceived stress measure by using the PSS scale. Revue Européenne de Psychologie Appliquée, 58, 227-239. http://dx.doi.org/10.1016/j.erap.2008.09.006

Chida, Y., \& Hamer, M. (2008). Chronic psychosocial factors and acute physiological responses to laboratory-induced stress in healthy populations: A quantitative review of 30 years of investigations. Psychological Bulletin, 134, 829-885. http://dx.doi.org/10.1037/a0013342

Chida, Y., \& Steptoe, A. (2009). Cortisol awakening response and psychosocial factors: A systematic review and meta-analysis. Biological Psychology, 80, 265-278. http://dx.doi.org/10.1016/j.biopsycho.2008.10.004

Childre, D., \& Cryer, B. (2000). From Chaos to Coherence: The Power to Change Performance. Boulder Creek, CA: Planetary.

Childre, D., \& Martin, H. (1999). The HeartMath Solution. San Francisco: HarperSanFrancisco.

Childre, D., \& Rozman, D. (2005). Transforming stress: The HeartMath solution for relieving worry, fatigue, and tension. Oakland: New Harbinger Publications.

Chrousos, G. P. (2009). Stress and disorders of the stress system. Nature Reviews Endocrinology, 5, 374-381. http://dx.doi.org/10.1038/nrendo.2009.106

Cohen, S., Karmak, T., \& Mermelstein, R. (1983). A global measure of perceived stress. Journal of Health and Social Behavior, 24, 385-396. http://dx.doi.org/10.2307/2136404

DeMoja, C. A., \& DeMoja, G. (1986). State-trait anxiety and motocross 
performance. Perceptual \& Motor Skills, 62, 107-110.

http://dx.doi.org/10.2466/pms.1986.62.1.107

Den, R., Toda, M., Nagasawa S, Kitamura, K., \& Morimoto, K. (2007). Circadian rhythm of human salivary Chromogranin A. BioMed Research International, 28, 57-60.

http://dx.doi.org/10.2220/biomedres.28.57

Elbaz, A., Metlaine, A., \& Leger, D. (2008). Actiwave, nouvelle technologie d'enregistrement du sommeil. Nouvelles Technologies, 5, 30-32.

Fales, C. L., Barch, D., M., Burgess, G. C., Schaefer, A., Mennin, D. S., Gray, J. R., et al. (2008). Anxiety and cognitive efficiency: Differential modulation of transient and sustained neural activity during a working memory task. Cognitive, Affective, \& Behavioral Neuroscience, 8, 239-253. http://dx.doi.org/10.3758/CABN.8.3.239

Friedman, B. H., \& Thayer, J. F. (1998). Anxiety and autonomic flexibility: A cardiovascular approach. Biological Psychology, 47, 243263. http://dx.doi.org/10.1016/S0301-0511(97)00027-6

Gais, S., \& Born, J. (2004). Declarative memory consolidation, mechanisms acting during human sleep. Learning \& Memory, 11, 679-685. http://dx.doi.org/10.1101/lm.80504

Grillon, C., Ameli, R., Foot, M., \& Davis, M. (1993). Fear-potentiated startle: Relationship to the level of state/trait anxiety in healthy subjects. Biological Psychiatry, 33, 566-574. http://dx.doi.org/10.1016/0006-3223(93)90094-T

Haftgoli, N., Favrat, B., Verdon, F., Vaucher, P., Bischoff, T., Burnand, B., \& Herzig, L. (2010). Patients presenting with somatic complaints in general practice: Depression, anxiety and somatoform disorders are frequent and associated with psychosocial stressors. BMC Family Practice, 11, 67. http://dx.doi.org/10.1186/1471-2296-11-67

Hanson, M. D., \& Chen, E. (2010). Daily stress, cortisol, and sleep: The Moderating role of childhood psychosocial environments. Health Psychology, 29, 394-402. http://dx.doi.org/10.1037/a0019879

Head, K. A., \& Kelly, G. S. (2009). Nutrients and botanicals for treatment of stress: Adrenal fatigue, neurotransmitter imbalance, anxiety, and restless sleep. Alternative Medicine Review, 14, 114-140.

Hobson, J. A., McCarley, R. W., \& Wyzinski, P. W. (1975). Sleep cycle oscillation: Reciprocal discharge by two brainstem neuronal groups. Science, 189, 55-58.

http://dx.doi.org/10.1126/science.1094539

Hobson, J. A., Stickgold, R., \& Pace-Schott, E. F. (1998). The neuropsychology of REM sleep dreaming. NeuroReport, 9, R1-R14. http://dx.doi.org/10.1097/00001756-199802160-00033

Horsten, M., Ericson, M., Perski A., Wamala S. P., Schenck-Gustafsson, K., \& Orth-Gomér, K. (1999). Psychosocial factors and heart rate variability in healthy women. Psychosomatic Medicine, 61, 49-57.

Jacquinet-Salord, M. C., Lang, T., Fouriaud, C., Nicoulet, I., \& Bingham, A. (1993). Sleeping tablet consumption, self reported quality of sleep, and working conditions. Journal of Epidemiology \& Community Health, 47, 64-68. http://dx.doi.org/10.1136/jech.47.1.64

Kalimo, R., Taris, T., \& Schaufeli, W. (2003). The effects of past and anticipated future downsizing on survivor wellbeing: An equity perspective. Journal of Occupational Health Psychology, 8, 91-109. http://dx.doi.org/10.1037/1076-8998.8.2.91

Kalimo, R., Tenkanen, L., Harma, M., Poppius, E., \& Heinsalmi, P. (2000). Job stress and sleep disorders: Findings from the Helsinki heart study. Stress Medicine, 16, 65-75.

http://dx.doi.org/10.1002/(SICI)1099-1700(200003)16:2<65::AID-S MI834>3.0.CO;2-8

Kang, M. G., Koh, S. B., Cha, B. S., Park, J. K., Baik, S. K., \& Chang, S. J. (2004). Job stress and cardiovascular risk factors in male workers. Preventive Medicine, 40, 583-588. http://dx.doi.org/10.1016/j.ypmed.2004.07.018

Lazarus, R. S. (1993). From psychological stress to the emotions: A history of changing outlooks. Annual Review of Psychology, 44, 1-21. http://dx.doi.org/10.1146/annurev.ps.44.020193.000245

Lehrer, P. M., Vaschillo, E., Vaschillo, B., Lu, S. E., Eckberg, D. L., Edelberg, R., Shih, W. J., Lin, Y., Kuusela, T. A., Tahvanainen, K. U. O., \& Hamer, R. M. (2003). Heart rate variability biofeedback increases baroreflex gain and peak expiratory flow. Psychosomatic Medicine, 65, 796-805. http://dx.doi.org/10.1097/01.PSY.0000089200.81962.19
Linton, S. J. (2004). Does work stress predict insomnia? A prospective study. British Journal of Health Psychology, 9, 127-136. http://dx.doi.org/10.1348/135910704773891005

Lucassen, P. J., Meerlo, P., Naylor, A. S., van Dam, A. M., Dayer, A. G., Fuchs, E., Omen, C. A., \& Czeh, B. (2010). Regulation of adult neurogenesis by stress, sleep disruption, exercise and inflammation: Implications for depression and antidepressant action. European Neuropsychopharmacology, 20, 1-17. http://dx.doi.org/10.1016/j.euroneuro.2009.08.003

Lucini, D., Norbiato, G., Clerici, M., \& Pagani, M. (2002). Hemodynamics and autonomic adjustments to real life conditions in humans. Hypertension, 39, 184-188. http://dx.doi.org/10.1161/hy0102.100784

Marquie, J. C., Foret, J., \& Queinnec, Y. (1999). Effects of age, working hours, and job content on sleep: A pilot study. Experimental Aging Research, 25, 421-427. http://dx.doi.org/10.1080/036107399243896

Malik, et al. (1996). Task force of the European society of cardiology and the North American society of pacing and electrophysiology. Heart rate variability. Standards of measurements, physiological interpretation and clinical use. Circulation, 93, 1043-1065. http://dx.doi.org/10.1161/01.CIR.93.5.1043

McCraty, R., Atkinson, M., Lipsenthal, L., \& Arguelles, L. (2003). Boulder Creek, CA: HeartMath Research Center, Institute of HeartMath, Report No. 03-014.

McCraty, R., Atkinson, M., Tiller, W. A., Rein, G., \& Watkins, A. D. (1995). The effects of emotions on short term heart rate variability using power spectrum analysis. American Journal of Cardiology, 76, 1089-1093. http://dx.doi.org/10.1016/S0002-9149(99)80309-9

McCraty, R., Atkinson, M., \& Tomasino, D. (2003). Impact of a Workplace Stress Reduction Program on Blood Pressure and Emotional Health in Hypertensive Employees. Journal of Alternative and Complementary Medicine, 9, 355-369. http://dx.doi.org/10.1089/107555303765551589

McCraty, R., Barrios-Choplin, B., Rozman, D., Atkinson, M., \& Watkins, A. D. (1998). The impact of a new emotional self-management program on stress, emotions, heart rate variability, DHEA and cortisol. Integrative Physiological and Behavioral Science, 33, 151-170. http://dx.doi.org/10.1007/BF02688660

McCraty, R., \& Tomasino, D. (2004). Heart rhythm coherence feedback: A new tool for stress reduction, rehabilitation, and performance enhancement. Proceedings of the First Baltic Forum on Neuronal Regulation and Biofeedback, Riga, Latvia, 2-5 November 2004.

Meerlo, P., Mistlberger, R. E., Jacobs, B. L., Heller, H. C., \& McGinty, D. (2009). New neurons in the adult brain: The role of sleep and consequences of sleep loss. Sleep Medicine Reviews, 13, 187-194. http://dx.doi.org/10.1016/j.smrv.2008.07.004

Mellman, T. A., \& Uhde, T. W. (1989). Electroencephalographic sleep in panic disorder: A focus on sleep-related panic attacks. JAMA Psychiatry, 46, 176-184. http://dx.doi.org/10.1001/archpsyc.1989.01810020080013

Nakane, H., Asami, O., Yamada, Y., Harada, T., Matsui, N., Kanno T., \& Yanaihara, N. (1998). Salivary chromogranin A as an index of psychosomatic stress response. Biomedical Research, 19, 401-406.

Nakata, A., Haratani, T., Takahashi, M., Kawakami, N., Arito, H., Kobayashi, F., \& Araki, S. (2004). Job stress, social support, and prevalence of insomnia in a population of Japanese daytime workers. Social Science \& Medicine, 59, 1719-1730.

http://dx.doi.org/10.1016/j.socscimed.2004.02.002

Nater, U. M., Rohleder, N., Gaab, J., Berger, S., Jud, A., Kirschbaum, C., \& Ehlert, U. (2005). Human salivary alpha-amylase reactivity in a psychosocial stress paradigm. International Journal of Psychophysiology, 55, 333-342. http://dx.doi.org/10.1016/j.ijpsycho.2004.09.009

Nater, U. M., La Marca, R., Florin, L., Moses, A., Langhans, W., Koller, M. M., \& Ehlert, U. (2006). Stress-induced changes in human salivary alpha-amylase activity-associations with adrenergic activity. Psychoneuroendocrinology, 31, 49-58. http://dx.doi.org/10.1016/j.psyneuen.2005.05.010

Niskanen, J. P., Tarveinen, M. P., Ranta-aho, P. O., \& Karjalainen, P. A. (2004). Software for advanced HRV analysis. Computer Methods and Programs in Biomedicine, 76, 73-81. 
http://dx.doi.org/10.1016/j.cmpb.2004.03.004

Nishida, M., Pearsall, J., Buckner, R. L., \& Walker, M. P. (2009). REM sleep, prefrontal theta, and the consolidation of human emotional memory. Cerebral Cortex, 19, 1158-1166. http://dx.doi.org/10.1093/cercor/bhn155

Ohira, T., Diez Roux, A. V., Prineas, R. J., Kizilbash, M. A., Carnethon, M. R., \& Folsom, A. R. (2008). Associations of psychosocial factors with heart rate and its short-term variability: Multi-ethnic study of atherosclerosis. Psychosomatic Medicine, 70, 141-146.

Parati, G., Mancia, G., Di Rienzo, M., \& Castiglioni, P. (2006). Point: Cardiovascular variability is/is not an index of autonomic control of circulation. Journal of Applied Physiology, 101, 676-678.

http://dx.doi.org/10.1152/japplphysiol.00446.2006

Payne, J. D., \& Nadel, L. (2004). Sleep, dreams, and memory consolidation: The role of the stress hormone cortisol. Learning Memory, 11, 671-678. http://dx.doi.org/10.1101/lm.77104

Plihal, W., \& Born, J. (1999). Memory consolidation in human sleep depends on inhibition of glucocorticoid release. Neuroreport, 10, 2741-2747. http://dx.doi.org/10.1097/00001756-199909090-00009

Poleshuck, E. L., Bair, M. J., Kroenke, K., Damush, T. M., Tu, W. Z., Wu, J. W., Krebs, E. E., \& Giles, D. E. (2009). Psychosocial stress and anxiety in musculoskeletal pain patients with and without depression. General Hospital Psychiatry, 31, 116-122.

http://dx.doi.org/10.1016/j.genhosppsych.2008.10.003

Porges, S. W. (1995). Orienting in a defensive world: Mammalian modifications of our evolutionary heritage. A polyvagal theory. Psychophysiology, 32, 301-318.

http://dx.doi.org/10.1111/j.1469-8986.1995.tb01213.x

Reynolds, C. F., Shaw, D. H., Newton, T. F., Coble, P. A., \& Kupfer, D. J. (1983). EEG sleep in outpatients with generalized anxiety, a preliminary comparison with depressed outpatients. Psychiatry Research, 8, 81-89. http://dx.doi.org/10.1016/0165-1781(83)90094-X

Riemann, D., Berger, M., \& Voderholzer, U. (2001). Sleep deprivation-results from psychobiological studies: An overview. Biological Psychology, 57, 67-103. http://dx.doi.org/10.1016/S0301-0511(01)00090-4

Sade, S., Bar-Eli, M., Bresler, S., \& Tenenbaum, G. (1990). Anxiety, self-control and shooting performance. Perceptual and Motor Skills, $71,3-6$.

Sollers, J. J. 3rd, Buchanan, T. W., Mowrer, S. M., Hill, L. K., \& Thayer, J. F. (2007). Comparison of the ratio of the standard deviation of the R-R interval and the root mean squared successive differences (SD/rMSSD) to the low frequency-to-high frequency (LF/HF) ratio in a patient population and normal healthy controls. Biomedical Sciences Instrumentation, 43, 158-163.

Spielberger, C. D. (1966). Theory and research on anxiety. Anxiety and behavior. New York: Academic press.

Spielberger, C. D., Gorsuch, R. L., \& Lushene, R. E. (1970). State-trait anxiety inventory manual. Palo Alto, CA: Consulting Psychologists Press.
Spielberger, C. D. (1975). Anxiety: State-trait-process. In C. D. Spielberger, \& I. G. Sarason (Eds.), Stress and anxiety (pp. 115-143). New York: Wiley.

Spoormaker, V. I., \& van den Bout, J. (2005). Depression and anxiety complaints; relations with sleep disturbances. European Psychiatry, 20, 243-245. http://dx.doi.org/10.1016/j.eurpsy.2004.11.006

Sterling, P., \& Eyer, J. (1988). Allostasis: A new paradigm to explain arousal pathology. In S. Fisher, \& J. reason (Eds.), Handbook of life stress, cognition and health (pp. 631-651). John Wiley and Sons Ltd.

Sushecki, D., Machado, R. B., \& Tiba, P. A. (2009). Stress-induced sleep rebound: Adaptative behaviour and possible mechanisms. Sleep Science, 2, 151-160.

Thayer, R. E. (1967). Measurement of activation through self-report. Psychological Reports, 20, 663-678.

Thayer, R. E. (1978). Factor analytic and reliability studies on the Activation-Deactivation Adjective Check List. Psychological Reports, 42, 747-756. http://dx.doi.org/10.2466/pr0.1978.42.3.747

Thayer, R. E. (1986). Activation-Deactivation Adjective Check List (AD ACL): Current overview and structural analysis. Psychological Reports, 58, 607-614. http://dx.doi.org/10.2466/pr0.1986.58.2.607

Thayer, R. E. (1987). Energy, tiredness, and tension effects of a sugar snack versus moderate exercise. Journal of Personality and Social Psychology, 52, 119-125.

http://dx.doi.org/10.1037/0022-3514.52.1.119

Thayer, R. E. (1989). The biopsychology of mood and arousal. Oxford: Oxford University Press.

Thayer, R. E., Newman R., \& McClain, T. M. (1994). Self-regulation of mood: Strategies for changing a bad mood, raising energy, and reducing tension. Journal of Personality and Social Psychology, 76, 910-925. http://dx.doi.org/10.1037/0022-3514.67.5.910

Trousselard, M., Cian, C., Barraud, P. A., Ferhani, O., Roux, A., Claverie, D., Canini, F., \& Baert, P. (2009). Physiological and psychological effects of escape from a sunken submarine on shore and at sea. Aviation, Space, and Environmental Medicine, 80, 850-856. http://dx.doi.org/10.3357/ASEM.2503.2009

Vahtera, J., Kivimaki, M., Pentti, J., Linna, A., Virtanen, M., Virtanen, P., \& Ferrie, J. (2004). Organisational downsizing, sickness absence, and mortality: 10-town prospective cohort study. British Medical Journal, 328, 555. online version.

Vgontzas, A. N., Bixler, E. O., \& Kales, A. (2000). Sleep, sleep disorders, and stress (pp. 449-457). San Diego: Academic Press.

Watson, D., \& Clark, L. A. (1994). Introduction to the special issue on personality and psychopathology. Journal of Abnormal Psychology, 103, 3-5. http://dx.doi.org/10.1037/h0092429

Wessel, N., Voss, A., Malberg, H., Ziehmann, C., Voss, H. U., Schirdewan, A., Meyerfeldt, U., \& Kurths, J. (1990). Nonlinear analysis of complex phenomena in cardiological data. Herzschrittmachertherapie und Elektrophysiologie, 11, 159-173. http://dx.doi.org/10.1007/s003990070035 